\title{
Beta-Blockers in High-Risk Outpatients with Chronic Obstructive Pulmonary Disease are Associated with All-Cause Mortality - The STATUETTE Cohort Study
}

\author{
Mathias Damkjær (D) \\ Charlotte Suppli Ulrik (D) ${ }^{1,2}$ \\ Nina Godtfredsen (D) ${ }^{1,2}$ \\ Kjell EJ Håkansson (iD) \\ 'Department of Respiratory Medicine, \\ Copenhagen University Hospital - \\ Hvidovre, Hvidovre, Denmark; ${ }^{2}$ Institute \\ of Clinical Medicine, University of \\ Copenhagen, Copenhagen, Denmark
}

Background: Beta-blockers have been proposed to improve COPD-related outcomes, yet studies report conflicting results. We aimed to investigate the effect of beta blockers on timeto-first exacerbation and all-cause mortality in high-risk COPD outpatients.

Methods: All COPD outpatients managed at the Department of Respiratory Medicine, Copenhagen University Hospital - Hvidovre, Denmark in 2016 were followed for 3.5 years in this retrospective, registry-based cohort study. Outcomes were time-to-first acute exacerbation of COPD (AECOPD) or death. The association was estimated using timevarying crude and multivariable Cox proportional hazard regression adjusted for age, sex, BMI, use of COPD medication, smoking status, cardiovascular disease and COPD severity.

Results: The cohort comprised 950 COPD outpatients, mean age 71 (SD 11) years, and $\mathrm{FEV}_{1} 44 \%$ predicted (IQR 33\%; 57\%). The annual exacerbation rate was 0.88 (SD 1.68) and 211 patients (22\%) had a history of hospitalization requiring AECOPD within 12 months. Of the enrolled patients, $247(26 \%)$ were prescribed beta blockers. Beta-blocker use was associated, although with borderline significance, with increased all-cause mortality (HR 1.37 (95\% CI, 0.99 to $1.89, \mathrm{p}=0.059)$ ). On the other hand, beta blocker use did not reduce the risk of AECOPD (HR $=0.89(95 \%$ CI 0.71 to $1.10 ; \mathrm{p}=0.270))$, which remained nonsignificant after stratifying for severity of exacerbations.

Conclusion: We found an association between beta blocker use and all-cause mortality in high-risk COPD outpatients. No association was found between beta blocker use and risk of AECOPD.

Keywords: chronic obstructive pulmonary disease, cardiovascular disease, exacerbations, beta-blockers, mortality

\section{Plain Language Summary}

What is already known on this topic:

- An association between beta-blocker use and reduced risk of exacerbations and mortality has been reported in observational studies. A single RCT has reported an increased risk of hospitalization following beta-blocker use in COPD patients without prior indication for beta-blocker use.

- Results from observational studies on beta-blocker therapy and COPD-related outcomes in COPD patients with concomitant CVD diverge, leaving the role of betablocker therapy in COPD yet to be elucidated.
Correspondence: Kjell EJ Håkansson Department of Respiratory Medicine, Copenhagen University Hospital Hvidovre, Kettegård Allé 30, Hvidovre, 2650, Denmark

Email kjell@kjell.dk 
What this study adds:

- This 3.5-year retrospective cohort study including 950 patients found an association between beta-blocker use and increased all-cause mortality, whereas no association was found between the risk of acute exacerbations and beta-blocker use.

- Considering the new evidence that has emerged, more studies on beta-blocker use in COPD patients, even in COPD patients with CVD, are highly needed. Currently, beta-blockers should only be prescribed for COPD patients based on established indications.

\section{Background}

Chronic obstructive pulmonary disease (COPD) and cardiovascular disease (CVD) are leading causes of morbidity and mortality worldwide. ${ }^{1}$ Patients with COPD have a large unmet need for prognosis-improving therapies besides treatments, such as pulmonary rehabilitation, smoking cessation and maintenance therapy with longacting bronchodilators and inhaled steroids. ${ }^{2-4}$

There is a well-described association between COPD and CVD, in which pulmonary and vascular inflammation and damage caused by long-term exposure to tobacco smoke or other noxious gases serve as a common link between the two. ${ }^{5}$ A two-fold increase in the odds of having CVD in COPD patients relative to COPD-free controls has been reported. ${ }^{6}$ It has been hypothesized, based on this close association, that therapies used in the treatment of CVD could be of importance for the treatment of COPD, particularly in those COPD patients having concomitant CVD. ${ }^{7}$ One of the proposed therapies is betablockers, as increased neurohumoral sympathetic activity driven by a sympatico-vagal imbalance has been demonstrated in $\mathrm{COPD},{ }^{8}$ suggesting that modulating betareceptor activity could affect COPD outcomes.

A reluctance towards treating COPD patients with beta-blockers exists, possibly due to a theoretical concern of causing bronchial contraction by blocking beta-2-adrenoreceptors in the pulmonary epithelium ${ }^{9}$ as well as direct antagonism with commonly used long-acting beta-2-agonists and thereby precipitate reduction of the lung function and a worsening of symptoms in COPD patients. The concerns have resulted in undertreatment of COPD patients with a guideline-based indication for betablockers, ${ }^{10}$ despite no existing evidence supporting these theoretical concerns and a Cochrane review reported that cardioselective beta-blockers did not cause any adverse respiratory effects in COPD patients. ${ }^{11-13}$
While a recent randomized, placebo-controlled clinical trial on metoprolol in COPD without concomitant CVD $\left(\mathrm{BLOCK}_{\mathrm{COPD}}{ }^{14}\right)$ was terminated early due to futility and patient-reported adverse events, retrospective observational studies have reported the benefits of beta-blocker treatment on COPD-related outcomes, such as exacerbations and mortality. ${ }^{15}$ As such, findings on the potential risks and/or benefits of beta-blocker use in COPD vary with study design, outcomes and populations chosen, further complicating the already difficult task of providing optimal treatment for COPD and related comorbidities.

In the present study, we aimed to examine the associations between beta blocker use, time to exacerbation and all-cause mortality over 3.5 years in a real-world evidence setting consisting of unselected high-risk COPD outpatients managed in secondary respiratory care.

\section{Methods}

\section{Study Design and Setting}

The present study is a retrospective cohort study using data from patient records and a nationwide medication database. It included patients from a single center using a fixed time follow-up interval. Further details of cohort selection and characteristics have been published previously. $^{16}$

The study was conducted at the Respiratory Outpatient Clinic, Copenhagen University Hospital - Hvidovre, Hvidovre, Denmark. All patients with a current COPD diagnosis (confirmed by spirometry and assessment by a respiratory specialist) and a scheduled visit during 2016 were included and followed from date of routine visit (index date) to August 2019 or to date of death. All patients were considered to be in a stable phase at inclusion. All Danish citizens are covered by a national public health insurance with tax-funded free access to healthcare.

\section{Ethics}

Study approvals were given by the Danish Patient Safety Authority (ref. 3-3013-3198/1) and the Capital Region of Copenhagen's Data Safety Board (ref. P-2019-674). As per Danish law, access to patient journals is granted by the Danish Patient Safety Authority and does not require informed consent.

\section{Data Collection}

Data was collected using unique, national Danish civil registration numbers ${ }^{17}$ to combine individual electronic 
patient records with vital status, laboratory- and dispensed prescription data.

Hospital admissions, disease severity, comorbidities and routine visit assessment data, such as pulmonary function tests, were accessed using electronic patient journals (Sundhedsplatformen (Epic Inc., USA)). Dispensed prescription data from January 2014 to August 2019 was supplied by the Danish National Health Service Prescription Registry. ${ }^{18}$ Medication status was based on ATC-codes, as described in Appendix 1.

\section{Definitions}

Exposure to beta-blockers was defined as a dispensed betablocker prescription as follows: Persistent user (dispensed prescription of a beta-blocker 121 days prior to index date), New user (blocker dispensed after index date but before end of follow-up) or Non-user (no beta-blocker redemption during study period).

Outcomes were defined as follows:

1. All-cause mortality was defined as categorial yes or no during the follow-up period.

2. Acute exacerbation (AECOPD) was defined, as previously validated, ${ }^{19,20}$ as a composite outcome of:

a. Moderate exacerbation: defined as redemption of a short-term prednisolone (maximum of 20 tablets of $25 \mathrm{mg}$ in one day) with or without concurrent antibiotics.

b. Severe exacerbation: defined as administration of P.O. or i.v. corticosteroids and hospitalization due to AECOPD ( $\geq 24$ hours) based on ICD-10 DJ46.

The first occurring AECOPD event (regardless of severity) was chosen as the date of the composite outcome.

The Global Initiative for Obstructive Lung Disease (GOLD) 2020 guidelines $^{21}$ were used to describe disease severity. Medication status was based on redeemed prescriptions four months prior to the index date. CVD comorbidities were defined as follows, based on active or previous ICD-10-codes: acute coronary syndrome (I24.9), chronic ischemic heart disease (I25), diabetes mellitus type 1 or 2 (E10, E11), reduced ejection fraction of less than $40 \%$ according to journal records, hypertension (I10), peripheral vascular disease (I74), atrial fibrillation (I48), pulmonary embolism (I26) or stroke (I64).
Use of long-term supplemental oxygen therapy (LTOT) and non-invasive ventilation (NIV) was defined as a completed order during hospitalization, or an outpatient visit for either therapy during or 12 months prior to the study period.

\section{Statistical Analyses}

Continuous variables were presented as either median (interquartile range (IQR)) or mean (standard deviation (SD)). Categorical variables were presented as counts (\%). Missing values were presented as an absolute number for each variable. No sample size calculations were performed prior to the study.

Crude (beta-blocker use only) and multivariable (betablocker use and confounders) Cox proportional hazard regressions were used to estimate the association between beta-blocker use and time to exacerbation or time to death. Beta-blocker use was considered a time-varying covariate in all models. Estimates are presented as hazard ratios (HR) with 95\% confidence intervals (CI).

Death was deemed a competing endpoint in time to exacerbation analyses, and as such risk time was censored at the time of death. Schoenfeld residuals were used to evaluate the proportional hazards assumption. Violating variables were adjusted by hazard stratification.

The covariates used in the multivariable analysis were age, sex, body mass index (BMI), COPD medication use, smoking status, and severity of airflow limitation as defined by GOLD. Selection of covariates was performed by evaluating the change in beta-blocker use hazard between models with and without the specific covariate, and if sufficient change was introduced, the variable was included as a covariate. Additional models with interaction between beta-blocker use and CVD and inhaled corticosteroids (ICS) were performed due to clinical suspicion of interaction. Finally, moderate and severe exacerbation sub-analyses with AECOPD as a single outcome were performed using the same multivariable analysis as described above.

To correct for immortal time bias in retrospective studies with medication use as exposure variables, a Mantel Byar $^{22}$ approach was used as previously described, ${ }^{16}$ see Figure 1. Multiple imputation using a multivariate chained equation, assuming missingness at random, with 1000 imputations was performed on missing values with the mice package. ${ }^{23}$ All analyses were performed using $\mathrm{R}$ (The R Foundation, Vienna, AU) version 4.0.3 and a significance level of $\alpha=0.05$ 


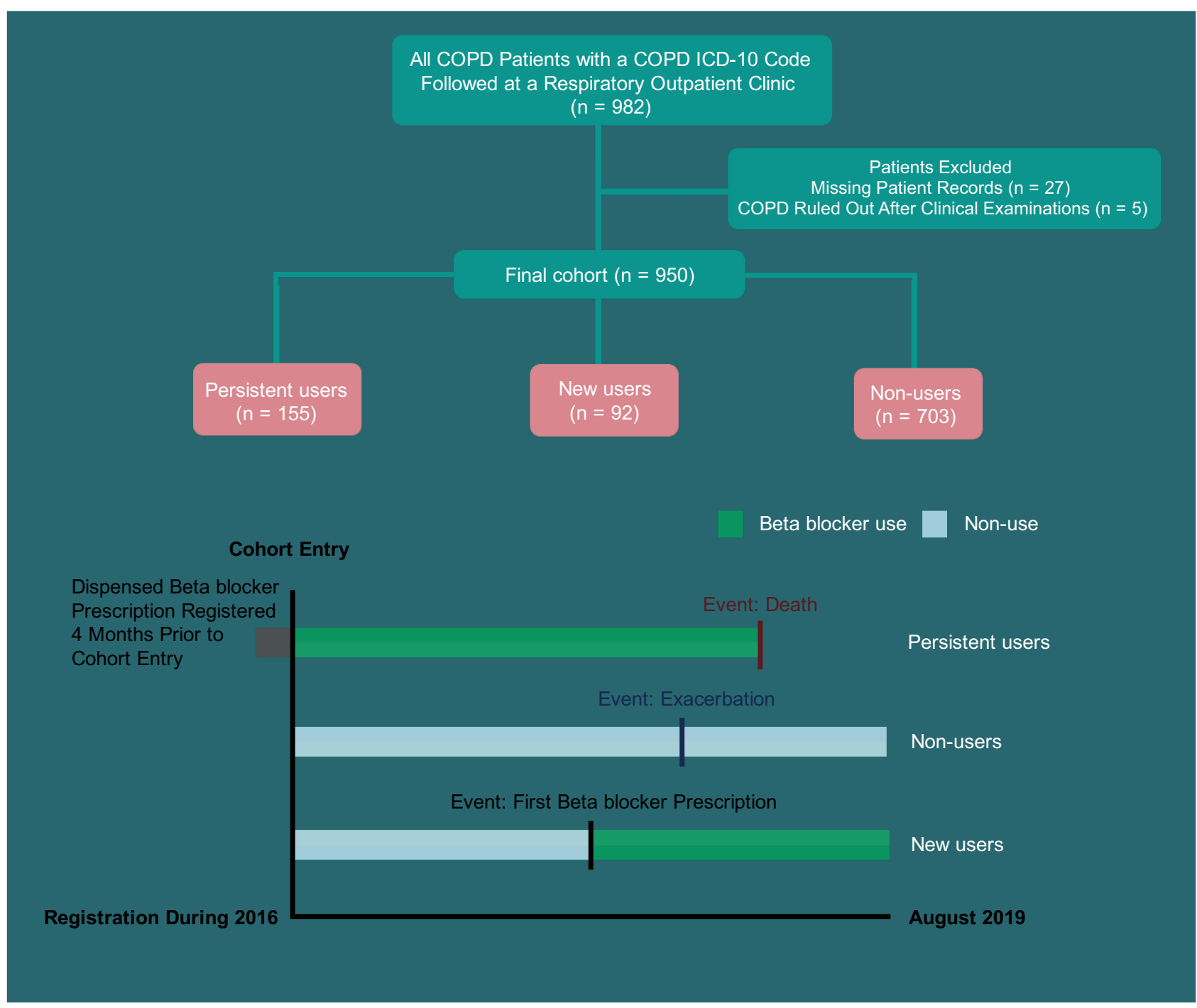

Figure I Participants and study design overview in a retrospective cohort study of beta-blocker use in unselected high-risk COPD patients followed at a university hospital respiratory outpatient clinic.

Abbreviation: COPD, chronic obstructive pulmonary disease.

\section{Results}

A total of 982 patients were screened for eligibility in the study. The final cohort comprised 950 COPD patients having available records and fulfilling all inclusion criteria (Figure 1), with $448(47 \%)$ male and mean age 71 years (SD 11). In the cohort, 247 (26\%) were current smokers and 665 (70\%) were ex-smokers, and the median pack-years (current- and exsmokers) were 43 (IQR 30; 51). The median $\mathrm{FEV}_{1}$ was $44 \%$ (IQR 33; 57) of the predicted value and the most common disease severity in GOLD 2020 classifications were B and D (34\% and 36\%, respectively) (Table 1).

Of the between-group differences, beta-blocker users were older, had slightly higher mean BMI, were more likely to be of male sex and had slightly more median pack years of smoking. Furthermore, asthma was more prevalent in the non-user group, but the amount of redeemed ICS prescriptions pointed to uncertainty about the validity of the registered asthma diagnosis (Table 1). No difference in GOLD classification, Medical Research Council (MRC)-scores, 12-month exacerbation history, smoking status nor maintenance COPD-therapy were found between beta-blocker users and non-users (Table 1).

In the cohort, 247 were defined as beta-blocker users, with $92(37.2 \%)$ being defined as 'New users'. The most used beta-blockers were metoprolol $(\mathrm{n}=178(71.5 \%))$ and carvedilol $(n=44(17.7 \%))$, respectively.

In terms of cardiovascular comorbidity, 623 (69\%) patients were classified as having at least one CVD diagnosis; of these, 233 (94\%) had been dispensed a betablocker prescription during the study period. 
Table I The Demographics of 950 COPD Patients at a University Hospital Outpatient Clinic, Arranged by Beta-Blocker Treatment Status

\begin{tabular}{|c|c|c|c|c|}
\hline & $\begin{array}{l}\text { Total, } \\
\mathrm{N}=950^{\mathrm{a}}\end{array}$ & $\begin{array}{l}\text { Beta-Blocker Users, } \\
N=247^{a}\end{array}$ & $\begin{array}{l}\text { Non-Users, } \\
N=703^{a}\end{array}$ & p-value ${ }^{b}$ \\
\hline Male (sex) & $448(47 \%)$ & $137(55 \%)$ & $311(44 \%)$ & 0.003 \\
\hline Age & $71(11)$ & $74(8)$ & $70(11)$ & $<0.001$ \\
\hline BMI & $25.5(5.8)$ & $26.4(5.8)$ & $25.2(5.7)$ & $<0.001$ \\
\hline Missing values & 30 & 2 & 28 & \\
\hline History of smoking & & & & 0.104 \\
\hline Current smoker & $247(26 \%)$ & $52(21 \%)$ & $195(28 \%)$ & \\
\hline Ex-smoker & $665(70 \%)$ & $186(75 \%)$ & $479(68 \%)$ & \\
\hline Non-smoker & $37(3.9 \%)$ & $9(3.6 \%)$ & $28(4 \%)$ & \\
\hline Missing values & 1 & 1 & 0 & \\
\hline Pack years of smoking for current and ex-smokers & $43(30,51)$ & $45(34,55)$ & $40(30,50)$ & 0.006 \\
\hline Missing values & 74 & 13 & 61 & \\
\hline Predicted FEV (\%) & $44(33,57)$ & $45(35,57)$ & $44(32,57)$ & 0.128 \\
\hline Missing values & 1 & 1 & 0 & \\
\hline MRC & $3.30(1.21)$ & $3.40(1.13)$ & $3.27(1.24)$ & 1.60 \\
\hline Missing values & 11 & 1 & 10 & \\
\hline LTOT & $146(15 \%)$ & $35(14 \%)$ & $111(16 \%)$ & 0.544 \\
\hline History of severe exacerbations (previous Iy) & $211(22 \%)$ & $55(22 \%)$ & $156(22 \%)$ & $>0.999$ \\
\hline History of NIV or intubation-requiring exacerbation(s) & $128(13 \%)$ & $38(15 \%)$ & $90(13 \%)$ & 0.307 \\
\hline GOLD A-D groups & & & & 0.512 \\
\hline A & $219(24 \%)$ & 49 (21\%) & $170(25 \%)$ & \\
\hline B & $308(34 \%)$ & $84(36 \%)$ & $224(33 \%)$ & \\
\hline C & $57(6.3 \%)$ & $13(5.5 \%)$ & 44 (6.5\%) & \\
\hline $\mathrm{D}$ & $327(36 \%)$ & 89 (38\%) & $238(35 \%)$ & \\
\hline Missing values & 39 & 12 & 27 & \\
\hline \multicolumn{5}{|l|}{ Comorbidities } \\
\hline Atrial fibrillation & $157(17 \%)$ & $100(40 \%)$ & $57(8.1 \%)$ & $<0.001$ \\
\hline Hypertension & $469(49 \%)$ & $176(7 \mid \%)$ & $293(42 \%)$ & $<0.001$ \\
\hline Stable ischemic heart disease & 79 (8.3\%) & $54(22 \%)$ & 25 (3.6\%) & $<0.001$ \\
\hline History of ACS & 59 (6.2\%) & $40(16 \%)$ & $19(2.7 \%)$ & $<0.001$ \\
\hline Diabetes type I or II & $140(15 \%)$ & $58(23 \%)$ & $82(12 \%)$ & $<0.001$ \\
\hline Stroke & $102(11 \%)$ & $31(13 \%)$ & $71(10 \%)$ & $<0.001$ \\
\hline Congestive heart failure & $76(8.0 \%)$ & $63(26 \%)$ & $13(1.8 \%)$ & $<0.001$ \\
\hline Cancer (any type) & $128(13 \%)$ & $4 \mid(17 \%)$ & $87(12 \%)$ & 0.118 \\
\hline Peripheral vascular disease & $57(6.0 \%)$ & $28(11 \%)$ & 29 (4.1\%) & $<0.001$ \\
\hline Osteoporosis & $24 I(25 \%)$ & $52(21 \%)$ & $189(27 \%)$ & 0.084 \\
\hline Concomittant asthma & $176(19 \%)$ & $25(10 \%)$ & $|5|(2 \mid \%)$ & $<0.001$ \\
\hline Total cholesterol (mM) & $4.62(1.62)$ & $4.23(1.20)$ & $4.78(1.10)$ & $<0.001$ \\
\hline Missing values & 196 & 22 & 174 & \\
\hline Single bronchodilator (LABA or LAMA) & $818(86 \%)$ & $206(83 \%)$ & $612(87 \%)$ & 0.153 \\
\hline Dual bronchodilators (LABA and LAMA) & $260(27 \%)$ & $59(24 \%)$ & $201(29 \%)$ & 0.179 \\
\hline ICS & $520(55 \%)$ & $132(53 \%)$ & $388(55 \%)$ & 0.634 \\
\hline
\end{tabular}

${ }^{\text {a Notes: }}{ }^{\text {a }}$ Statistics presented: $\mathrm{n}(\%)$; mean (SD); median (IQR). ${ }^{\mathrm{b}}$ Statistical tests performed: Chi-square test of independence; Wilcoxon rank-sum test.

Abbreviations: LABA, long-acting beta2-agonist; LAMA, long-acting muscarinic antagonist; ICS, inhaled corticosteroids; ACS, acute coronary syndrome; LTOT, Long-term oxygen therapy; NIV, non-invasive Ventilation. 
A total of 2121 events were observed in 600 patients during the median follow-up period of 2.82 years (IQR 2.63, 3.10). During this time, 373 (39\%) and 344 (36\%) patients experienced at least one moderate or severe exacerbation, respectively, and 220 (23\%) patients died. The yearly mean exacerbation rates for exacerbating patients were 0.80 / person-year (SD 1.29) and 0.80/person-year (SD 1.36) for moderate and severe exacerbations, respectively. The mean time until first exacerbation was 723 and 770 days for moderate and severe exacerbations, respectively. When stratified by beta-blocker use, users had an overall exacerbation frequency of 0.55/person-year (SD 0.83) and for non-users the corresponding frequency was $0.63 /$ person-year (SD 1.31).

\section{The Effect of Beta-Blocker Use on Exacerbations}

In the time-varying, crude Cox regression model betablocker use was not found to be associated with reduced risk of AECOPD (HR $=0.96(95 \%$ CI 0.78 to $1.19 ; \mathrm{p}=$ 0.73). Adjusting for smoking status, GOLD 2020 classification, age, sex, BMI, COPD medication use did not influence the association between beta-blocker use and time to AECOPD (HR $=0.89(95 \%$ CI 0.71 to $1.10 ; \mathrm{p}=$ 0.270)), nor did further adjustment for CVD (Table 2).

When stratifying for moderate and severe exacerbations in a sub-analysis using the same model, beta-blocker use was not associated with a reduction in time to AECOPD $(\mathrm{HR}=0.88(95 \% \mathrm{CI} 0.69$ to $1.12 ; \mathrm{p}=0.299)$ and $\mathrm{HR}=0.86$ ( $95 \%$ CI 0.68 to $1.09 ; \mathrm{p}=0.218$ ), respectively).

\section{The Effect of Beta-Blocker Use on All-Cause Mortality}

In the time-varying, crude Cox regression model, a significant increase in mortality for beta-blocker users was observed when compared to non-users, HR $=1.89(95 \%$ CI 1.42 to $2.50, \mathrm{p}=<0.001)$. Adjusting for sex, smoking status, longterm oxygen therapy, non-invasive ventilation or intubation requiring exacerbations, history of severe exacerbations, age, BMI and GOLD 2020 classification did not influence the association between beta-blocker use and mortality, HR = 1.60 (95\% CI, 1.19 to $2.15 ; \mathrm{p}=0.002)$. When further adjusting for CVD, the association weakened, with the HR for mortality in the beta-blocker group decreasing slightly, $\mathrm{HR}=1.37$ (95\% CI, 0.99 to $1.89 ; \mathrm{p}=0.059$ ) (Table 3).

Table 2 A Time-Varying Covariate Cox Proportional Hazard Regression for Association of Beta-Blocker Use and Hazard Ratio (HR) for Time to First Exacerbation in 950 COPD High-Risk Outpatients

\begin{tabular}{|c|c|c|c|c|c|c|c|c|c|}
\hline & \multicolumn{3}{|c|}{ Crude } & \multicolumn{3}{|c|}{ Adjusted } & \multicolumn{3}{|c|}{ Interaction CVD } \\
\hline & HR & $95 \% \mathrm{Cl}$ & p-value & HR & $95 \% \mathrm{Cl}$ & p-value & HR & $95 \% \mathrm{Cl}$ & p-value \\
\hline Beta-blocker use & 0.96 & $0.78,1.19$ & 0.730 & 0.89 & $0.71,1.10$ & 0.270 & 0.83 & $0.66,1.05$ & 0.129 \\
\hline Age & & & & 1.02 & I.01, 1.03 & $<0.001$ & 1.02 & I.01, 1.03 & $<0.001$ \\
\hline Female & & & & 1.06 & $0.89,1.27$ & 0.504 & 1.08 & $0.90,1.30$ & 0.398 \\
\hline \multicolumn{10}{|l|}{ BMI } \\
\hline$<18.5$ & & & & 1.16 & $0.86,1.58$ & 0.323 & 1.17 & $0.86,1.59$ & 0.315 \\
\hline$\geq 18.5-24.9$ & & & & I & I & & I & & \\
\hline$\geq 25-29.9$ & & & & 1.07 & $0.87,1.33$ & 0.519 & 1.07 & $0.86,1.33$ & 0.538 \\
\hline$>30$ & & & & 0.96 & $0.74,1.24$ & 0.777 & 0.95 & $0.73,1.24$ & 0.709 \\
\hline Single long-acting bronchodilator & & & & 0.98 & $0.69,1.40$ & 0.930 & 0.98 & $0.68,1.40$ & 0.896 \\
\hline Dual long-acting bronchodilators & & & & 1.08 & $0.85,1.36$ & 0.534 & 1.08 & $0.86,1.36$ & 0.505 \\
\hline ICS & & & & 1.44 & $1.14,1.81$ & 0.003 & 1.45 & I.I4, I.83 & 0.002 \\
\hline \multicolumn{10}{|l|}{ Cardiovascular disease diagnoses } \\
\hline None & & & & & & & I & I & \\
\hline I & & & & & & & 0.98 & $0.78,1.23$ & 0.839 \\
\hline$\geq 2$ & & & & & & & 1.14 & $0.90,1.46$ & 0.280 \\
\hline
\end{tabular}

Note: The analysis was stratified for smoking status and Global Initiative for Chronic Obstructive Lung Disease severity staging 2020 classification.

Abbreviations: BMI, body mass index; $\mathrm{Cl}$, confidence interval; CVD, cardiovascular disease; HR, hazard ratio; ICS, inhaled corticosteroids. 
Table 3 A Time-Varying Covariate Cox Proportional Hazard Regression for Association of Beta-Blocker Use and Hazard Ratio (HR) for All-Cause Mortality in 950 COPD High-Risk Outpatients

\begin{tabular}{|c|c|c|c|c|c|c|c|c|c|}
\hline & \multicolumn{3}{|c|}{ Crude } & \multicolumn{3}{|c|}{$\begin{array}{l}\text { Adjusted Model, without } \\
\text { CVD }\end{array}$} & \multicolumn{3}{|c|}{$\begin{array}{l}\text { Adjusted Model, with } \\
\text { CVD }\end{array}$} \\
\hline & HR & $95 \% \mathrm{Cl}$ & p-value & HR & $95 \% \mathrm{Cl}$ & p-value & HR & $95 \% \mathrm{Cl}$ & p-value \\
\hline Beta-blocker use & 1.89 & $1.42,2.50$ & $<0.001$ & 1.60 & $1.19,2.15$ & 0.002 & 1.37 & $0.99,1.89$ & 0.059 \\
\hline Age & & & & 1.05 & $1.03,1.07$ & $<0.001$ & 1.04 & $1.03,1.06$ & $<0.001$ \\
\hline $\begin{array}{l}\text { BMI } \\
<18.5 \\
\geq 18.5-24.9 \\
\geq 25-29.9 \\
>30\end{array}$ & & & & $\begin{array}{l}1.22 \\
1 \\
0.69 \\
0.64\end{array}$ & $\begin{array}{l}0.79, I .87 \\
I \\
0.49,0.98 \\
0.42,0.98\end{array}$ & $\begin{array}{l}0.375 \\
0.038 \\
0.405\end{array}$ & $\begin{array}{l}1.27 \\
1 \\
0.68 \\
0.60\end{array}$ & $\begin{array}{l}0.82,1.95 \\
I \\
0.48,0.96 \\
0.39,0.92\end{array}$ & $\begin{array}{l}0.279 \\
0.029 \\
0.020\end{array}$ \\
\hline $\begin{array}{l}\text { GOLD I-4 spirometric grade } \\
\text { GOLD I } \\
\text { GOLD } 2 \\
\text { GOLD } 3 \\
\text { GOLD } 4\end{array}$ & & & & $\begin{array}{l}1 \\
1.06 \\
1.08 \\
1.37\end{array}$ & $\begin{array}{l}\mathrm{I} \\
0.42,2.70 \\
0.43,2.74 \\
0.53,3.59\end{array}$ & $\begin{array}{l}0.894 \\
0.866 \\
0.516\end{array}$ & $\begin{array}{l}1 \\
1.00 \\
1.03 \\
1.27\end{array}$ & $\begin{array}{l}\mathrm{I} \\
0.39,2.53 \\
0.41,2.61 \\
0.48,3.31\end{array}$ & $\begin{array}{l}0.995 \\
0.948 \\
0.629\end{array}$ \\
\hline History of severe exacerbations (previous Iy) & & & & 1.45 & $1.07,1.97$ & 0.017 & 1.43 & $1.05,1.94$ & 0.023 \\
\hline $\begin{array}{l}\text { History of NIV or Intubation-requiring } \\
\text { exacerbation(s) }\end{array}$ & & & & 2.02 & $1.45,2.80$ & $<0.001$ & 2.07 & I.49, 2.87 & $<0.001$ \\
\hline $\begin{array}{l}\text { Cardiovascular disease diagnosis } \\
\text { None } \\
\text { । } \\
\geq 2\end{array}$ & & & & & & & $\begin{array}{l}\mathrm{I} \\
1.08 \\
1.50\end{array}$ & $\begin{array}{l}\mathrm{I} \\
0.72,1.60 \\
\mathrm{I} .02,2.23\end{array}$ & $\begin{array}{l}0.920 \\
0.042\end{array}$ \\
\hline
\end{tabular}

Note: The analysis was stratified for sex, long-term oxygen therapy and smoking status.

Abbreviations: BMI, body mass index; Cl, confidence interval; CVD, cardiovascular disease; GOLD, Global Initiative for Chronic Obstructive Lung Disease; HR, hazard ratio.

\section{Interaction Analyses}

No interaction was observed between beta-blocker use and CVD in either model $(\mathrm{p}=0.164)$. Interaction analyses did not change the associations found, but increased the statistical uncertainty in both models, causing nonsignificance in the mortality model. Likewise, no interaction was found between beta-blocker and ICS use in both models and the potential interaction did not alter the results $(\mathrm{p}=0.069)$.

\section{Discussion}

In this cohort study consisting of 950 COPD outpatients followed for 3.5 years, we found a borderline significant association between beta-blocker use and increased allcause mortality. No association was found between betablocker use and risk of AECOPD after adjusting for age, sex, BMI, GOLD 2020 classification, smoking status and concurrent CVD.

\section{Beta-Blocker Use and Exacerbations}

The present study, and the lack of association found between beta-blocker use and AECOPD risk, is in discordance with previous meta-analyses and observational studies reporting an association between use of beta-blockers and a reduced risk of exacerbations. ${ }^{15,24}$ The nationwide Danish publication by Rasmussen et $\mathrm{al}^{25}$ reported an association between beta-blocker use and reduced risk of exacerbations in COPD patients following hospitalization with a diagnosis of AMI. In contrast, the RCT BLOCK $\mathrm{COPD}^{13}$ included patients without $\mathrm{CVD}$ and reported an increased risk of severe AECOPD (but not time to exacerbation) in beta-blocker users. The direct antagonism of beta-blockers with commonly used long-acting beta2-agonists has been proposed previously as a possible explanation for this increased risk of hospitalization during exacerbations in COPD patients treated with betablockers. $^{12}$ 
Indeed, differences in study populations are seemingly important as Rutten et $\mathrm{al}^{26}{ }^{26}$ Rasmussen et $\mathrm{al}^{25}$ and the present study all include varying degrees of patients with CVD and thus indications for beta blockers. As CVD might be both underdiagnosed and undertreated in $\mathrm{COPD},{ }^{10}$ differences in results could be attributed to an unknown amount of undiagnosed CVD in the studies enrolling unselected COPD patients. Furthermore, varying study populations in terms of risk (primary care ${ }^{26}$ versus secondary care), study design (possible lack of power, immortal time bias adjustment), etc., could further complicate direct comparison.

\section{Beta-Blocker Use and Mortality}

The present study found a borderline significant association between beta-blocker use and all-cause mortality, in accordance with a Swedish observational study including patients with severe COPD published by Ekström et al. ${ }^{27}$ Notably, Ekström et al used a similar design as in the present study, incorporating adjustment for both CVD and immortal time bias. Other observational studies report reduced mortality, and a recent meta-analysis concludes a general tendency towards reduced risk of mortality. ${ }^{15}$ Differing results might depend on study population factors, such as disease severity and treatment, with both Ekström et $\mathrm{al}^{27}$ and the present study primarily including patients with advanced COPD. Furthermore, differences in study design, including adjustment for immortal time bias, may very well explain differing results, as immortal time bias often leads to intervention risk reduction in pharmacoepidemiologic studies. ${ }^{22}$ Of note, mortality reduction has been reported in an observational study by $\mathrm{Su}$ et $\mathrm{al}^{2}{ }^{28}$ despite correction for immortal time bias, in COPD patients hospitalized with a diagnosis of AMI.

RCT studies with beta-blocker therapy for COPD are rare, with the recent study BLOCK $\mathrm{COPD}^{14}$ demonstrating increased all-cause mortality in patients without concomitant CVD receiving $50 \mathrm{mg}$ metoprolol daily. However, BLOCK COPD ${ }^{14}$ was terminated early due to futility and increased risk of hospitalization following AECOPD. As such, the result on a secondary outcome like all-cause mortality with few recorded events, should be cautiously interpreted.

\section{Implications}

Our results add to the evidence that beta-blocker use should be tailored to individual patients according to guidelines for CVD management, as it may have detrimental effects in some COPD patients. The present study highlights the need for more well-designed studies regarding the effect and causality of risk/benefit of betablockers in COPD patients. One such study is currently being conducted in Sweden. ${ }^{29}$ However, according to our study and the study by Ekström et $\mathrm{al}^{27}$ studies are also warranted in patients with concurrent CVD to represent real-life COPD populations, which are currently often excluded from clinical trials. A possible explanation has been proposed that the observed increased risk of mortality is driven by unmeasured biasses, such as confounding by indication in the observational study designs, ${ }^{27}$ but it is vital that well-designed pragmatic trials are performed to support these claims. In contrast, should beta-blockers prove to be detrimental in some subpopulations or indications in COPD patients, other superior (or non-inferior) treatment alternatives in common diseases such as hypertension and atrial fibrillation should be considered. ${ }^{30,31}$

\section{Limitations}

The present study is limited by residual bias from the observational study design using historical data from patient records and a national registry; however, the use of robust statistical measures reduces the overall impact of known biases, such as immortal time bias. Unmeasured confounding by indication could lead to an increased mortality, while the association did persist after adjusting for concurrent CVD. A differential misclassification bias due to misdiagnosis of $\mathrm{CV}$ events, especially in the beta-blocker group, might have increased AECOPD frequency in this group; however, this would not mask a potential detrimental effect on AECOPD. Furthermore, cardiovascular comorbidities are based on ICD-10 diagnoses, which may not reflect the severity of individual diseases. The single-center recruitment from a university hospital outpatient clinic limits the external validity, yet low amounts of missing data and loss to followup strengthen internal validity. Since beta-blocker use-data is based on prescription redemption, adherence to redeemed doses cannot be reliably assessed.

\section{Conclusion}

We found an association between beta-blocker use and allcause mortality, but not AECOPD risk, in high-risk COPD outpatients. However, pragmatic clinical trials are severely needed to elucidate the possible detrimental, or even beneficial, effects of beta-blockers in certain COPD populations. 


\section{Data Sharing Statement}

Data available upon reasonable requests, however, as per Danish law approval from the Danish Patient Safety Authority and the Capital Region of Copenhagen's Data Safety Board might be required.

\section{Author Contributions}

All authors made substantial contributions to conception and design, acquisition of data, or analysis and interpretation of data; took part in drafting the article or revising it critically for important intellectual content; agreed to submit to the current journal; gave final approval of the version to be published; and agreed to be accountable for all aspects of the work.

\section{Funding}

There is no funding to report.

\section{Disclosure}

KEJH reports personal fees from TEVA, personal fees from AstraZeneca, personal fees from Chiesi, outside the submitted work; CSU reports personal fees from AstraZeneca, GSK, TEVA, Novartis, Chiesi, BoehringerIngelheim, SanofiGenzyme, ALK-Abello, MundiPharma, Orion Pharma and Actelion, outside the submitted work. NG reports personal fees from AstraZeneca, BoehringerIngelheim, Novartis and GSK, outside the submitted work. The authors report no other conflicts of interest in this work.

\section{References}

1. The Lancet - Global Burden of Disease. Available from: https://www. thelancet.com/gbd. Accessed September 13, 2020.

2. Maqsood U, Ho TN, Palmer K, et al. Once daily long-acting beta 2-agonists and long-acting muscarinic antagonists in a combined inhaler versus placebo for chronic obstructive pulmonary disease. Cochrane Database Syst Rev. 2019;(3). doi:10.1002/14651858

3. Anthonisen NR, Connett JE, Murray RP. Smoking and lung function of Lung Health Study participants after 11 years. Am J Respir Crit Care Med. 2002;166(5):675-679. doi:10.1164/rccm.2112096

4. Mccarthy B, Casey D, Devane D, Murphy K, Murphy E, Lacasse Y. Pulmonary rehabilitation for chronic obstructive pulmonary disease. Cochrane Database Syst Rev. 2015;(2). doi:10.1002/14651858. CD003793.pub3

5. Sin DD, Paul Man SF. Why are patients with chronic obstructive pulmonary disease at increased risk of cardiovascular diseases? The potential role of systemic inflammation in chronic obstructive pulmonary disease. Circulation. 2003;107(11):1514-1519. doi:10.1161/01. CIR.0000056767.69054.B3

6. Chen W, Thomas J, Sadatsafavi M, FitzGerald JM. Risk of cardiovascular comorbidity in patients with chronic obstructive pulmonary disease: a systematic review and meta-analysis. Lancet Respir Med. 2015;3(8):631-639. doi:10.1016/S2213-2600(15)00241-6
7. Morgan AD, Zakeri R, Quint JK. Defining the relationship between COPD and CVD: what are the implications for clinical practice? Ther Adv Respir Dis. 2018;12:1-16. doi:10.1177/1753465817750524

8. Andreas S, Anker SD, Scanlon PD, Somers VK. Neurohumoral activation as a link to systemic manifestations of chronic lung disease. Chest. 2005;128(5):3618-3624. doi:10.1378/chest.128.5.3618

9. Ikeda T, Anisuzzaman ASM, Yoshiki H, et al. Regional quantification of muscarinic acetylcholine receptors and $\beta$-adrenoceptors in human airways. Br J Pharmacol. 2012;166(6):1804-1814. doi:10.1111/ j.1476-5381.2012.01881.x

10. Rasmussen DB, Bodtger U, Lamberts $\mathrm{M}$, et al. Beta-blocker, aspirin, and statin usage after first-time myocardial infarction in patients with chronic obstructive pulmonary disease: a nationwide analysis from 1995 to 2015 in Denmark. Eur Hear J. 2020;6(1):23-31. doi:10.1093/ehjqcco/qcy063

11. Sr S, Tm O, Ee S. Cardioselective beta-blockers for chronic obstructive pulmonary disease. Cochrane Database Syst Rev. 2005. doi:10.1002/14651858.CD003566.pub2

12. Baker JG, Wilcox RG. $\beta$-Blockers, heart disease and COPD: current controversies and uncertainties. Thorax. 2017;72(3):271-276. doi:10.1136/thoraxjnl-2016-208412

13. Leitao Filho FS, Choi L, Sin DD. Beta-blockers in chronic obstructive pulmonary disease: the good, the bad and the ugly. Curr Opin Pulm Med. 2021;27(2):125-131. doi:10.1097/MCP.0000000000000748

14. Dransfield MT, Voelker H, Bhatt SP, et al. Metoprolol for the prevention of acute exacerbations of COPD. $N$ Engl J Med. 2019;381 (24):2304-2314. doi:10.1056/nejmoa1908142

15. Gulea C, Zakeri R, Alderman V, Morgan A, Ross J, Quint JK. Betablocker therapy in patients with COPD: a systematic literature review and meta-analysis with multiple treatment comparison. Respir Res. 2021;22(1):1-14. doi:10.1186/s12931-021-01661-8

16. Damkjær M, Håkansson K, Kallemose T, Ulrik CS, Godtfredsen N. Statins in high-risk chronic obstructive pulmonary disease outpatients: no impact on time to first exacerbation and all-cause mortality the STATUETTE cohort study. Int J Chron Obstruct Pulmon Dis. 2021;16:579-589. doi:10.2147/COPD.S296472

17. Pedersen CB. The Danish civil registration system. Scand J Public Health. 2011;39(7 Suppl):22-25. doi:10.1177/1403494810387965

18. Pottegård A, Schmidt SAJ, Wallach-Kildemoes H, Sørensen HT, Hallas J, Schmidt M. Data resource profile: the Danish national prescription registry. Int J Epidemiol. 2017;46(3):798. doi:10.1093/ije/dyw213

19. Ingebrigtsen TS, Marott JL, Lange P, Hallas J, Nordestgaard BG, Vestbo J. Medically treated exacerbations in COPD by GOLD 1-4: a valid, robust, and seemingly low-biased definition. Respir Med. 2015;109(12):1562-1568. doi:10.1016/j.rmed.2015.10.015

20. Reilev M, Pottegård A, Lykkegaard J, Søndergaard J, Ingebrigtsen TS, Hallas J. Increased risk of major adverse cardiac events following the onset of acute exacerbations of COPD. Respirology. 2019;24(12):1183-1190. doi:10.1111/resp.13620

21. GOLD guidelines. Available from: https://goldcopd.org/wp-content/ uploads/2019/12/GOLD-2020-FINAL-ver1.2-03Dec19_WMV.pdf. Accessed August 13, 2021.

22. Suissa S. Immortal time bias in pharmacoepidemiology. $A m$ J Epidemiol. 2008;167(4):492-499. doi:10.1093/aje/kwm324

23. van Buuren S, Groothuis-Oudshoorn K. mice: multivariate imputation by chained equations in R. J Stat Softw. 2011;45(3):1-67. doi:10.18637/jss.v045.i03

24. Yang YL, Xiang ZJ, Yang JH, Wang WJ, Xu ZC, Xiang RL. Association of $\beta$-blocker use with survival and pulmonary function in patients with chronic obstructive pulmonary and cardiovascular disease: a systematic review and meta-analysis. Eur Heart J. 2021;41 (46):4415-4422. doi:10.1093/eurheartj/ehaa793

25. Rasmussen DB, Bodtger U, Lamberts M, et al. Beta-blocker use and acute exacerbations of COPD following myocardial infarction: a Danish nationwide cohort study. Thorax. 2020;75(11):928-933. doi:10.1136/thoraxjnl-2019-214206 
26. Rutten FH, Zuithoff NPA, Hak E, Grobbee DE, Hoes AW. BBlockers may reduce mortality and risk of exacerbations in patients with chronic obstructive pulmonary disease. Arch Intern Med. 2010;170(10):880-887. doi:10.1001/archinternmed.2010.112

27. Ekström MP, Hermansson AB, Ström KE. Effects of cardiovascular drugs on mortality in severe chronic obstructive pulmonary disease: a time-dependent analysis. Am J Respir Crit Care Med. 2013;187 (7):715-720. doi:10.1164/rccm.201208-1565OC

28. Su TH, Chang SH, Kuo CF, Liu PH, Chan YL. B-blockers after acute myocardial infarction in patients with chronic obstructive pulmonary disease: a nationwide population-based observational study. PLoS One. 2019;14(3):1-14. doi:10.1371/journal.pone.0213187

29. Sundh J, Magnuson A, Montgomery S, Andell P, Rindler G, Fröbert O. Beta-blockeRs to patieNts with CHronIc Obstructive puLmonary diseasE (BRONCHIOLE)-Study protocol from a randomized controlled trial. Trials. 2020;21(1):1-8. doi:10.1186/ s13063-019-3907-1
30. Williams B, Mancia G, Spiering W, et al. 2018 practice guidelines for the management of arterial hypertension of the European society of cardiology and the European Society of Hypertension ESC/ESH Task Force for the Management of Arterial Hypertension. Blood Pressure. 2018;36:314-340. doi:10.1097/HJH.0000000000001961

31. Hindricks G, Potpara T, Dagres N, et al. 2020 ESC Guidelines for the diagnosis and management of atrial fibrillation developed in collaboration with the European Association for Cardio-Thoracic Surgery (EACTS). Eur Heart J. 2021;42(5):373-498. doi:10.1093/eurheartj/ ehaa612

\section{Publish your work in this journal}

The International Journal of COPD is an international, peer-reviewed journal of therapeutics and pharmacology focusing on concise rapid reporting of clinical studies and reviews in COPD. Special focus is given to the pathophysiological processes underlying the disease, intervention programs, patient focused education, and self management protocols. This journal is indexed on PubMed Central, MedLine and CAS. The manuscript management system is completely online and includes a very quick and fair peer-review system, which is all easy to use. Visit http://www.dovepress.com/testimonials.php to read real quotes from published authors. 